\title{
Paz perpetua y federación europea: la crítica de Leibniz a Saint-Pierre ${ }^{1}$
}

\section{Perpetual Peace and European Federation: Leibniz's critique of Saint-Pierre}

\section{Concha Roldán ${ }^{2}$}

\author{
Instituto de Filosofía, CSIC (España)
}

Recibido: 17-07-14

Aprobado: 12-08-14

\section{Resumen}

En las últimas décadas ha sido creciente el protagonismo del opúsculo de Kant, Hacia la paz perpetua (1795), inspirado en las reflexiones del Abbé de Saint-Pierre. Leibniz, sin embargo, no suele ser considerado entre los antecedentes políticos de las reflexiones kantianas sobre la paz perpetua. Éste trabajo pretende poner el acento en la originalidad de la aportación leibniziana, subrayando su crítica a los planteamientos del Abbé de Saint-Pierre. Para Leibniz existiría una "imposibilidad política" para establecer la "paz perpetua"; por eso, propone trascender el nivel del federalismo político y situarse en el campo de la cooperación científica donde se carezca de intereses o, mejor dicho, éstos sean universalizables, a fin de poder instaurar las garantías necesarias para una paz duradera.

\footnotetext{
${ }^{1}$ Este trabajo se ha realizado en el marco de los proyectos de investigación "Leibniz en español II" (FFI2010-15914), "Filosofía de la historia y valores en la Europa del siglo XXI" (FFI2008-04279/ FISO) y "Enlightenment and Global History" (ENGLOBE: Marie Curie Inicial Training Network: FP7-PEOPLE-2007-1-1-ITN).

2 (roldan@ifs.csic.es). Concha Roldán es Profesora de Investigación en el Instituto de Filosofía del CSIC, del que es actualmente Directora, e Investigadora principal del proyecto europeo Marie Curie "Philosophy of History and Globalisation of Knowledge. Cultural Bridges Between Europe and Latin America" (WORLDBRIDGES) y del I+D "Prismas filosófico-morales de las crisis" (PRISMAS FFI2013-42935-P). Tiene numerosas publicaciones sobre filosofía moderna e Ilustración, ética, feminismo y filosofía de la historia, entre las que cabe destacar: Entre Casandra y Clio. Una historia de la Filosofía de la historia (Akal, Madrid, 2005; $1^{\mathrm{a}}$ ed. 1997); "La idea de tolerancia en Leibniz", en Forjadores de la tolerancia. Claroscuros en el pensamiento europeo de los siglos XVII y XVIII, M ' José Villaverde y Christian Laursen, eds., Tecnos, Madrid, 2011; o New Perspectives in Global History (con Daniel Brauer, Iwan d'Aprile y Günther Lottes, Wehrhahn Verlag, Hannover 2013).
} 
Palabras-clave: paz perpetua, guerras de religión, federalismo, Europa, ética universal, cooperación científica.

\begin{abstract}
Kant's short work Towards Perpetual Peace (1795), inspired in the reflections of the Abbot Saint-Pierre, has attracted attention during the last decades. Nonetheless, Leibniz is not generally considered as political predecessor of Kantian pondering on perpetual peace. This work intends to stress the originality of Leibniz's contribution, underlining his critique of the Abbot Saint-Pierre's proposals. For Leibniz there exists a "political impossibility" to establish perpetual peace. Therefore, he proposes to transcend the level of political federalism and, in order to implement the necessary guarantees for a lasting peace, he suggests to establish oneself in the field of scientific cooperation when one would lack interests, or rather, these would be possible to be universalised.
\end{abstract}

Key-words: Perpetual peace, wars of religion, federalism, Europe, universal ethic, scientific cooperation.

\title{
1. Remontando la corriente desde Kant a Saint-Pierre. El protagonismo de Leibniz.
}

La posibilidad de una paz perpetua en Europa surge de la mano de la reflexión sobre una federación de estados, a la vez que están paradójicamente emergiendo los nacionalismos europeos con toda su pujanza. En estos planteamientos, Kant se presenta como un punto de inflexión y cobra un gran protagonismo durante los dos últimos siglos, que ha sido revitalizado las últimas décadas en los discursos europeístas, presentando a su autor como el primer filósofo de nuestra era que no sólo se ocupó de estudiar las medidas políticas necesarias para asegurar la paz, sino que también elevó a deber moral la supresión de la guerra, tal como resume su famosa formulación: "la razón práctico-moral expresa en nosotros su veto irrevocable: no debe haber guerra"3. Sin duda, el mérito kantiano reside en su análisis del concepto de paz y sus presupuestos desde un punto de vista filosófico, como pone de manifiesto el subtítulo de su ensayo: "Un proyecto filosófico", a la vez que sistematiza las ideas sobre el federalismo entre Estados libres, sobre el derecho cosmopolita universal o sobre la supresión de los ejércitos permanentes, pilares sobre los que se levantará el derecho internacional de las Naciones Unidas. Ahora bien, sus planteamientos no dejan de ser deudores

${ }^{3}$ Metaphysik der Sitten, Ak. VI, 354 (trad. castellana de A. Cortina y J. Conill, Madrid,Tecnos, 1989, p.195).

Araucaria. Revista Iberoamericana de Filosofia, Política y Humanidades, año 16, no 32 . Segundo semestre de 2014. Pp. 111-133. ISSN 1575-6823 e-ISSN 2340-2199 doi: 10.12795/araucaria.2014.i32.06 
de algunos proyectos anteriores, como los de Charles Irenée Castel de SaintPierre - más conocido como Abbé de Saint-Pierre- o Rousseau ${ }^{4}$, por nombrar a los más cercanos, pues entre los predecesores del movimiento pacifista que exige como condición la unificación europea habría que citar, entre otros, a $\mathrm{E}$. de Rotterdam, L. Vives, S. Frank, E. Crucé, M. de Béthune (Duque de Sully), A. Comenius, W. Penn o al mismo Leibniz, quien sin embargo, no suele ser considerado entre los antecedentes del ensayo Zum ewigen Frieden (1795) de Kant. En un trabajo anterior que celebraba el bicentenario del ensayo kantiano, me ocupé de estudiar su "prehistoria"; en éste, me centraré en la crítica leibniziana al proyecto de paz perpetua de Saint-Pierre, sobre todo en lo que pueda tener de crítica avant la lettre de los planteamientos kantianos, para mostrar la actualidad del punto de vista político de Leibniz sobre la unidad europea, buscando las raíces históricas de una problemática que aún ocupa las discusiones de los foros internacionales.

Aunque en 1712 ya había publicado en Köln una Mémoire pour rendre la paix perpétuelle en Europe, el escrito del Abbé de Saint-Pierre conocido como Projet pour rendre la Paix perpétuelle en Europe consta de tres volúmenes publicados por Antoine Schouten en Utrech, habiendo sido publicados los dos primeros en 1713 bajo el título mencionado y el tercero en 1717 bajo el título Projet de Traité pour rendre la paix perpetuelle entre les souveraines chrétiens; los dos primeros volúmenes fueron traducidos en 1714 al inglés (A Project for Settling an Everlasting Peace in Europa), lo que denota la expectación creada por la cuestión en su momento, pero todos desaparecieron pronto de la circulación hasta que en 1981 fueran reeditados en edición facsímil por Simone Goyard-Fabre ${ }^{6}$, siendo únicamente conocidas y comentadas durante los siglos XVIII y XIX las versiones abreviadas del Proyecto, que Saint-Pierre publicara en 1729 y 1738 . En este trabajo nos referiremos fundamentalmente a los dos primeros volúmenes publicados por Saint-Pierre, que fueron los conocidos y comentados por Leibniz en sus Observations sur le projet d'une paix perpétuelle de M. L'Abbé de Saint-Pierre', así como a los que hace referencia

${ }^{4}$ Cf. R. R. Aramayo, La balance d'Europe: Saint-Pierre chez Frédéric II, Rousseau, Leibniz et Kant [en H. Poser, ed.: Nihil sine ratione. VII. Internationaler Leibniz-Kongress, Berlin, Technische Universität, 2001], pp. 25-32.

${ }^{5}$ Cf. Los prolegómenos del proyecto kantiano sobre la paz perpetua [en R. R. Aramayo, J. Muguerza y C. Roldán, eds.: La paz y el ideal cosmopolita de la Ilustración (En el bicentenario de La paz perpetua de Kant), Madrid, Tecnos, Madrid, 1996] pp. 125-154. Sobre los antecedentes de la comunidad europea en relación con los proyectos de paz es interesante consultar: O. Asbach, Europa - Vom Mythos zur Imagined Community? Zur historischen Semantik 'Europas' von der Antike bis ins 17. Jahrhundert, München, Wehrhahn, 2011 y F.J. Espinosa Antón, Inventores de la paz, soñadores de Europa, Madrid, Biblioteca Nueva, 2012.

${ }^{6}$ Será esta edición de 719 páginas la que aquí manejaremos: Projet pour rendre la paix perpétuelle en Europe, ed. par S. Goyard-Fabre, Fayard, reedición de 1986 (citaremos como « Project » más año de publicación). Más sobre la historia y estructura de la obra cf. F.J. Espinosa y C. Roldán, loc. cit. pp. 57-69 y pp. 132-137, respectivamente.

7 Euvres de Leibniz, ed. de A. Foucher de Careil, París, Firmin Didot, 1859-1875, Tome 4. 
su breve correspondencia con Saint-Pierre, mantenida durante 1715 y 1716 , hasta un mes antes de la muerte del pensador de Leipzig 8 .

Saint-Pierre había querido contar con Leibniz expresamente entre sus interlocutores; buscando por todos los medios difundir sus ideas, necesitaba encontrar apoyos entre los pensadores de más renombre y, considerando a Leibniz como alguien que ejercía una especie de dictadura intelectual en Europa, su aprobación le era en extremo valiosa; se trataba, además, de uno de los hombres más susceptibles de interesarse en la idea, por su propia trayectoria intelectual, en la que no había escamoteado esfuerzos por conseguir la unidad política y religiosa del Imperio, ni había ahorrado especulaciones políticas destinadas a facilitar la eliminación de todos los elementos de discordia que azotaban a Europa. Así pues, enviará a Leibniz el 20 de enero de 1714 el texto de su Proyecto (los dos primeros volúmenes publicados en 1713 en Utrech), a través de quien considera la vía más segura, su viejo amigo Pierre Varignon -a quien había conocido en 1676 durante sus años de estudiante en Caen y con quien emprendiera viaje a París en $1680^{\circ}$ - a la sazón convertido en un gran matemático, miembro de la Academia de Ciencias de París y uno de los principales corresponsales de Leibniz.

El proyecto de Saint-Pierre era, sin duda, una propuesta altamente atractiva, pero que no encontró precisamente muchos adeptos entre sus coetáneos. Incluso aquellos que lo vieron con simpatía -como Fontenelle ${ }^{10}$, Mably, el propio Leibniz, Montesquieu o D'Alembert- no dejaron de encontrarle objeciones, mostrándose escépticos ante la realización de lo que parecía una utopía. Otros le ridiculizaron directamente, como Voltaire, quien dio muestras de su ironía acuñando para el abad el mote de "Saint-Pierre d'Utopie" o "bonzo SaintPierre"11. Pero la opinión más sarcástica procede de los políticos; incluso el "rey ilustrado" Federico II de Prusia, autor del Anti-Maquiavelo escribe en una carta a Voltaire: "El abate de Saint-Pierre me ha enviado un hermoso escrito sobre el modo de restablecer la paz en Europa y de consolidarla para siempre. La cosa es muy practicable... Para hacerla triunfar solo falta el consentimiento de los europeos y algunas otras bagatelas por el estilo" ${ }^{12}$.

${ }^{8}$ La última carta de Leibniz a Saint-Pierre está datada el 19 de Octubre de 1716; cf. Manuscrito, Archives du Ministère des Affaires étrangères, Paris, Acquisitions extraordinaires, Vol. 55, fol. 19v ${ }^{\circ}$ $20 v^{\circ}$. Leibniz murió el 14 de noviembre de ese mismo año. Sobre la correspondencia de Leibniz con Saint-Pierre, cf. Robinet, A., Correspondance G.W. Leibniz - Ch.-I. Castel de Saint-Pierre, Paris, Centre de philosophie du droit, 1995, pp. 104-119.

${ }^{9}$ Sobre la biografía de Saint-Pierre puede consultarse con provecho J. Drouet, L'abbé de SaintPierre, l'homme et l'oeuvre, Paris, Champion, 1912.

${ }^{10}$ Fontenelle fue otro de los amigos comunes de Saint-Pierre y Leibniz, facilitando la entrada del primero en la Academia Francesa de las Ciencias en 1695.

${ }^{11}$ Cf. Rescripto del Emperador de la China con motivo del proyecto de paz de perpetua (1761) [en Voltaire: Opúsculos satíricos y filosóficos, Alfaguara, Madrid, 1978] p. 246.

${ }^{12}$ Cf. Anti-Maquiavelo o Refutación del Príncipe de Maquiavelo, ed. de Roberto. R. Aramayo, Madrid, Centro de Estudios Constitucionales, 1995. 
A partir del Siglo de la Luces, la voluminosa obra de Saint-Pierre fue conocida fundamentalmente a través del "Resumen" y el "Comentario (o Juicio)" de ésta publicados por Rousseau en 1761 y 1782, respectivamente ${ }^{13}$. Es casi seguro que tanto Kant como Fichte o Saint-Simon tuvieron acceso a la extensa obra de Saint-Pierre solo por esta mediación de Rousseau, quien, si bien respetó las ideas esenciales del abad, no dejó de introducir su filosofía política en el desarrollo.

El autor de las tres críticas, lo mismo que Saint-Pierre ${ }^{14}$, hacía depender el logro de la paz mundial del establecimiento de una organización política internacional que adoptara la forma de una federación de Estados libres ${ }^{15}$ y lo mismo que su predecesor pensaba que "es posible representarse la posibilidad de llevar a cabo esta idea (realidad objetiva) de la federación (Föderalität), que debe extenderse paulatinamente a todos los Estados, conduciendo así a la paz perpetua". En este concepto kantiano de federación descansa la idea contemporánea de confederación europea, esto es, unión de Estados que conservan su autonomía política o soberanía; sin embargo, nos encontramos todavía muy lejos de la instauración de una paz perpetua, incluso en el seno de la vieja Europa. Esto nos lleva a plantearnos la cuestión de la interdependencia entre federalismo y paz, esto es, en qué medida ambos componentes se exigen mutuamente, como pretendía el pensador de Königsberg. ¿Constituye el federalismo un supuesto para que se dé la paz? En el fundamento mismo de la noción kantiana de federación radica a mi juicio cierta ambigüedad que conduce a simplificar en manera indebida un problema necesitado de no pocos matices y distinciones. A mi entender, la filosofía de Leibniz - sin emplear el concepto de "cosmopolitismo"- proporciona una base metafísica de tintes universalistas a los planteamientos federalistas, algo de lo que carecían las propuestas de Rousseau y del Abbé de Saint-Pierre, reducidas a Europa, y que luego retomará la propuesta cosmopolita de Kant.

El filósofo báltico tomaba, lo mismo que Saint-Pierre, a la "unión alemana" como modelo de federación que debía extenderse internacionalmente, de forma que un cuerpo político soberano servía de ejemplo para la constitución de lo que debería ser una confederación de estados soberanos. Y este supuesto será cuestionado por Leibniz, para quien el federalismo sólo puede servir como base a un nacionalismo que quiera evitar el absolutismo, debiendo buscarse otras vías de cooperación científica (República de las Letras, creación de Academias

\footnotetext{
${ }^{13}$ Cf. J.J. Rousseau, Resumen del Proyecto de Saint-Pierre, trad. de J. Rubio Carracedo, "Philosophica malacitana", 6 (1993) y Écrits sur L'Abbé de Saint-Pierre (1756-59) [en J. J. Rousseau, Oeuvres Completes. III. Écrits politiques, Paris, Bibliothèque de la Pléiade, 1964], pp. 561-682.

${ }_{14}$ Cf. Projet 1713,pp. 12 y 51.

15 "Föderalism freier Staaten", en Zum ewigen Frieden, Ak. VIII, 356 (trad. Castellana de J. Abellán, Madrid, Tecnos, 1985, p. 24). Cf. al respecto P. Riley, Eternal Peace Through Federalism in Kant's Political Philosophy [en P. Riley, Kant's Political Philosophy, New Yersey, Rowrnan and Littlefield, 1983], pp. 114-134.
} 
y Sociedades científicas) para la integración de los países europeos y, por ende, de todo el mundo; más aún, es imposible que resulte una federación "para la paz" (foedus pacificum) de la suma de intereses políticos y económicos antagónicos; entre Estados sólo pueden darse alianzas transitorias "para la guerra" contra o en defensa de un enemigo común; la paz sólo puede surgir, pues, en un ámbito meta-político, en el terreno desinteresado de la cooperación científica.

Podríamos decir sin temor a equivocarnos que la obra de Saint-Pierre ha sido tan inflacionariamente citada como realmente desconocida. Habitualmente se le suele relacionar, por su origen nobiliario y sus relaciones con la Iglesia católica, con el Antiguo Régimen, ignorándose o haciéndose caso omiso de aquellos escritos en los que Saint-Pierre critica el absolutismo de Luis XIV ${ }^{16}$ como su Polysynodie ${ }^{17}$, que le granjearon su expulsión de la Academia en 1718, llevándole a refugiarse primero en el Club de l'Entresol y cuando este fue cerrado en esos "espacios fronterizos" que constituían los salones literarios regentados por mujeres y que comenzaban a proliferar en la Francia de la época ${ }^{18}$, experiencias que le convertirán en un representante atípico de la Ilustración francesa o de lo que algunos autores han dado en llamar "la otra ilustración"19 en el contexto europeo. Sin duda, la razón última de que la propuesta de paz perpetua de Saint-Pierre fuera rechazada por los intelectuales y políticos franceses de la época, tachada de utópica e incluso ridiculizada hasta el extremo, residía en la crítica implícita que hacía al absolutismo de Luis XIV, con su política de guerras de conquista, que convertían a Europa en un campo de batalla permanente con el único fin de aumentar su megalomanía. La política francesa veía en la propuesta de federación europea del abad una disminución de su poder, algo que, por el contrario, despertaba las simpatías de Leibniz.

${ }^{16}$ Cf. al respecto el libro de O. Asbach, Staat und Politik zwischen Absolutismus un Aufklärung. Der Abbé de Saint-Pierre und die Herausbildung der französischen Aufklärung bis zur Mitte des 18. Jahrhunderts, Hildesheim-Zürich-New York, Georg Olms, 2005. Cf. también F.J. Espinosa Antón, loc. cit., pp. 58-60, quien nos hace reparar en la divisa republicana que imprime Saint-Pierre a las naciones aliadas en la consecución de su plan de paz: salus populi suprema lex est (Project 1717, 434).

${ }_{17}$ Discours sur la Polysynodie où l'on demontre que la Polysynodie, ou la pluralité des Conseils, est la forme de Ministère la plus avantageuse pour un roi, \& pour son Royaume, Amsterdam, $1718\left(2^{\mathrm{a}}\right.$ ed. 1719). Es de entender que la obra supusiera un escándalo, pues en ella se acomete la consideración de la política nacional francesa desde la perspectiva de un recorte considerable de la omnipotencia del monarca, gracias a un sistema de varios Consejos.

18 En el Club de 1'Entresol, fundado en 1720 como lugar de debate ético-político y cerrado por el cardenal Fleury en 1731, conoció Saint-Pierre a Montesquieu. Cf. E. York, Ancient, Mediaeval and Modern Leagues of Nations, London, The Swarthmore Press, 1919, p. 168. Cf asimismo F.J. Espinosa, loc. cit. p. 60 y C. Roldán, loc. cit. p. 137 y Philosophy for Ladies: diffusion or exclusion of knowledge in Enlightenment. The exclusion of women from institutionalised knowledge and the role of the salons in the dissemination of learning [en Dariusz Dolański, Anna Janczys, eds.: Images of/from Enlightenment, Zielona Góra, UZg., 2013], pp. 117-135.

${ }_{19}$ Cf. Alicia Puleo, La ilustración olvidada, Anthropos, Barcelona, 1993 (2011, 2ª ed.) y Julio Seoane, La ilustración heterodoxa, Fundamentos, Madrid, 1998. Cf. también C. Roldán, Transmisión y exclusión del conocimiento en la Ilustración: filosofia para damas y querelle des femmes, Arbor 731 (2008), pp. 457-470.

Araucaria. Revista Iberoamericana de Filosofia, Política y Humanidades, año 16, no 32 . Segundo semestre de 2014. Pp. 111-133. ISSN 1575-6823 e-ISSN 2340-2199 doi: 10.12795/araucaria.2014.i32.06 
Leibniz -además de criticar las carencias históricas del discurso- detectó y comentó con acierto esta veta más genuinamente política en el Proyecto de paz de Saint-Pierre y que hacía referencia a la tensión entre las propuestas federalistas en el seno de la vieja Europa -heredera del antiguo Imperio- y los incipientes nacionalismos, tendentes a imagen de Francia al absolutismo monárquico, enraizado en un paternalismo de corte ilustrado ${ }^{20}$. Con toda seguridad SaintPierre tuvo en cuenta los comentarios de Leibniz en la redacción de su tercer volumen del Proyecto (el que fuera publicado en 1717 en Utrech), así como en sus versiones abreviadas de 1729 y 1738. Este trabajo se propone, así, poner el acento en la originalidad de la aportación leibniziana, subrayando su crítica al Abbé de Saint-Pierre, a cuya propuesta de "proponer los medios para establecer la paz perpetua entre todos los estados cristianos" ${ }^{\prime 21}$ contrapondrá la de una confederación europea basada en una metafísica y ética universalistas, que Saint-Pierre reformulará en el tercer volumen y sus elaboraciones posteriores como un "cosmopolitismo ético" ${ }^{22}$ que, como sabemos, no será ajena al planteamiento kantiano.

\section{La crítica leibniziana al proyecto de paz perpetua del Abbé de Saint-Pierre}

Cuando el envío de Saint-Pierre llega a Hannover, Leibniz se encuentra en Viena, donde se preparaba precisamente el Tratado de Utrecht, así que hasta muchos meses después no leerá el Proyecto y redactará sus mencionadas Observaciones, que inicia con claras alabanzas hacia la propuesta del abad: "Por fin lo he leído con atención y estoy persuadido de que un proyecto semejante es en gran medida realizable, y que su ejecución será una de las cosas más útiles del mundo" ${ }^{\text {"23. }}$. Pero tras esta cortés entrada, da paso a una profunda crítica a la defensa que hace Saint-Pierre de su proyecto, centrándola en tres frentes: la ausencia y/o error de interpretación de los antecedentes históricos, la carencia de una perspectiva psicológico-antropológica en sus juicios y, lo más importante, su erróneo análisis político y jurídico de „los actores“, esto es, los estados cristianos que deberían adoptar dietas o tratados para introduir una confederación de estados en Europa y, sobre todo, los gobernantes de los mismos, con cuyo beneplácito -si no entusiasmo- habría que contarse. Estos serán también los elementos que Leibniz manejará certeramente en su correspondencia.

${ }^{20}$ Cf. Q. Racionero, Politische Aufklärung und Staattheorie bei Leibniz [en M. Buhr, ed.: Das geistige Erbe Europas, Napoles, Vivarium, 1993], pp. 517-39.

${ }^{21}$ Como indica en su Prefacio, Project 1713, p. 9.

22 Cf Project 1717, p. 627.

${ }^{23}$ Cf. Observations sur le projet d'une paix perpétuelle de M. L'Abbé de Saint-Pierre, en loc.cit. p. 328. 
Leibniz enviará su primera carta a Saint-Pierre el 7 de febrero de 1715 a través de Rémond de Montmort, a quien participa en un billete adjunto su escepticismo por la empresa, a pesar de las buenas intenciones y razones sólidas del abad: "Es bien cierto que si los hombres quisieran, podrían liberarse de tres grandes plagas, la guerra, la peste y el hambre. En cuanto a las dos últimas, cualquier soberano puede hacerlo; pero en contra de la guerra haría falta ese acuerdo entre los soberanos que es difícil de obtener"24. En la carta dirigida a Saint-Pierre (cortés, alabando la solidez y excelencia de su obra, pero a todas luces sin entusiasmo) repite Leibniz la misma idea: el problema fundamental, llevar a los hombres -esto es, a los monarcas- a querer la paz perpetua, no ha sido solucionado por el $\mathrm{abad}^{25}$.

No comparto con algunos autores que Leibniz no se toma en serio el proyecto de Saint-Pierre. Como mencionábamos al comienzo de este apartado, Leibniz lee con atención el largo y farragoso escrito del abad, convencido de que un proyecto tal sería factible y de gran utilidad para la humanidad, en el caso de que -y aquí entra en juego su realismo político- los más poderosos se interesaran por llevarlo a cabo. No es, pues, que el proyecto no sea factible y deseable, sino que no se puede pretender llevarlo a cabo desde la ingenuidad, es decir, desde la ignorancia de las pasiones humanas y de la ambición de los monarcas, llamados a acoger con recelo un plan que conducía al carácter definitivo de las fronteras que sancionaba, donde ningún territorio podía expandir sus límites al quedar vetada la posibilidad de cesiones, compras, conquistas, anexiones o sucesiones.

Según Leibniz, un proyecto que pretende establecer la paz perpetua no puede ignorar que el conflicto es connatural a los seres vivos, que se enfrentan por la incompatibilidad de sus intereses. Por eso había aludido irónicamente a la obra de Saint-Pierre un par de años antes de que éste le enviara su escrito: "He visto alguna referencia del proyecto del Sr. de Saint-Pierre para asegurar la paz perpetua en Europa. Me recuerda una leyenda en un cementerio con las palabras pax perpetua; ahora bien, los muertos ya no luchan, pero los vivos tienen un talante diferente; y los más poderosos no respetan tribunal alguno"26. Para que una propuesta como la de Saint-Pierre tuviera éxito haría falta, en su opinión, que los poderosos se pusieran de acuerdo en querer la paz, que otro Enrique IV

${ }^{24}$ Die Philosophischen Schriften von Gottfried Wilhelm Leibniz, ed. de C.I. Gerhardt, Berlin, Weidman, 1875-1890, III, p. 637. A partir de ahora citaré esta edición de las obras de Leibniz con las siglas "GP". La carta a Rémond está fechada el 11 de febrero de 1715. La cursiva es mía.

25 "Un soberano que lo desea puede preservar sus estados de la peste... Un soberano podría incluso salvar a sus Estados del hambre. Pero para hacer cesar la guerra haría falta que otro Enrique IV, junto con algunos grandes príncipes de su tiempo, se interesara por vuestro proyecto. Lo malo es que es difícil hacerlo entender a los grandes príncipes", Carta de Leibniz a Saint-Pierre, Hannover, 7 de febrero de 1715 [en Foucher de Careil, ob. cit., pp. 325-26].

${ }^{26}$ Carta a Grimarest del 4 de junio de 1712 [en Kortholt, Recueil de diverses pièces, Hamburgo, Vandenhoeck, 1734, p. 43]. Leibniz recuerda, sin duda, el ejemplo que mencionaba en un pasaje del Codex Iuris Gentium (1693): “... un bromista holandés después de haber colocado en la fachada de su casa, de acuerdo con la costumbre local, un cartel en el que se leía paz perpetua, dibujó debajo de esta frase un cementerio"; esta misma anécdota será recogida por Kant al comienzo de su ensayo sobre la paz. 
se interesara por su proyecto y propusiera a otros grandes príncipes establecer una sociedad de soberanos, cayendo por su propio peso que si los monarcas más poderosos hicieran esta propuesta, los otros la recibirían de buen grado ${ }^{27}$; y no le restaría mérito a la propuesta de Enrique $I^{28}$ la sospecha de que tuviera por finalidad derrocar a la casa de Habsburgo, pues "la ambición no es menos eficaz que el amor" y "haría falta que un gran príncipe tuviera el alma extremadamente depurada de mundanidades para propender a la restricción de su poder y a una renunciación formal al derecho de paz y guerra, con miras a tornar más felices a sus pueblos y a sus sucesores" 29 .

Leibniz hace saber al abad que hay que ser un "político sagaz", buen conocedor de la historia y de la psicología de los príncipes, para hacerles sugerente un proyecto de paz, pues sin ellos -o sea, sin su poder- no existe ninguna posibilidad de acción. Con esta finalidad, no estaría de más que SaintPierre (pensando en esa tercera edición de su obra que anuncia) se preocupara de adornar su escrito con algunos ejemplos históricos y trazos de erudición ${ }^{30}$, así como profundizar más en los conocimientos históricos que se refieren a la "unión alemana" que pretende tomar como modelo de la federación europea que propone ${ }^{31}$. La utilización del "cuerpo alemán" como modelo era, sin duda, poco acertada, tanto por la diferencia de sus orígenes históricos como por la divergencia de su finalidad política y fue, además, interpretada por sus compatriotas como una especie de traición.

Pero Leibniz no sólo critica a Saint-Pierre la posibilidad de realización del proyecto de paz perpetua. Además, señala otro punto débil en la argumentación del abad, aún en el supuesto de que se hubiera llevado a cabo una confederación por la paz entre todos los monarcas europeos, pues haría falta que las estipulaciones descansaran sobre sólidas garantías (cosa que Saint-Pierre a todas luces descuida), a fin de que ningún miembro de

${ }^{27}$ Cf. Observations, loc. cit., p. 330.

${ }^{28}$ Leibniz se está refiriendo a la obra de Maximilien de Béthune, duque de Sully, al servicio del mencionado rey, a quien atribuye su obra titulada Mémoires des sages et royales oeconomies d'Estat de Henry le Grand (1638). Según Sully, el rey Enrique IV habría sido el autor de un "gran proyecto" que contemplaba la constitución de una república europea formada por quince estados. No hay duda de que en el espíritu de Sully este proyecto "federativo" estaba destinado a conjurar la amenaza que los turcos hacían pesar sobre Europa, a la vez que suponía el medio coyuntural de oponerse al imperialismo de los Habsburgo. Cf. Observations, loc.cit.

${ }^{29}$ Carta a M. l'Abbé de S. Pierre, Hanover, 4 de abril de 1715, "Voprosy filosofii" 18 (1964), pp. 122 y 123.

${ }^{30}$ Cf. carta a Saint-Pierre, Hanover, 7 de febrero de 1715 (F. de C., 327) y Observations, loc. cit., pp. 328-329) No debería dejar de hacer referencia, por ejemplo, a las obras de Emeric Crucé, Le nouveau Cynée ou Discours des ocasions et moyens d'etablir une paix général et la liberté du commerce par tout le monde (1623), o del landgrave Ernest de Hesse-Rheinfels, Verus, sincerus et discretus catholicus contractus (1660), donde se exponen con anterioridad al suyo proyectos de paz universal. Me parece interesante resaltar que el programa de Crucé (tomando como protagonista a Cynéas, confidente del rey Pyrrhus) está unido, de manera muy original para la época, a las condiciones económicas del país, por lo que se sitúa mucho más cerca de Montchrestien, inventor de la economía política (Traité d'economie politique, 1615), que del humanismo erasmiano.

${ }^{31}$ Cf. Observaciones, loc. cit., pp. 332-336. Sobre este punto volveremos en el siguiente apartado. 
esa alianza pudiera abandonarla después arbitrariamente: “...si dos o tres jóvenes monarcas de los más poderosos se cansaran de las leyes que les son prescritas, y las quisieran infringir, ¿cómo impedírselo de otra manera que por una guerra cuyo éxito sería dudoso? No sería vano para este propósito que el mayor Banco de Europa estuviera en manos del Consejo General y que todos los príncipes tuvieran (cada uno proporcionalmente) millones depositados en dicho Banco, los cuales estarían allí tan seguros como en sus cofres y les proporcionarían incluso intereses. Así su capital no permanecería improductivo y serviría a su vez como una especie de caución burguesa" ${ }^{32}$. En la mente de Leibniz está el doble significado de Gewährleistung en alemán: "garantía” y "fianza", y su formación de jurista le lleva a hacer hincapié en un concepto fundamental, sobre el que insistirá Kant en su ensayo y que vertebra las investigaciones ético-políticas en torno al "principio de precaución" en la actualidad $^{33}$.

La propuesta de Leibniz es revolucionaria, digna de un diplomático con experiencia que no ignora que todo proyecto recibe su viabilidad del poder, de un político realista que sabe que hay que buscar estrategias de control para evitar que ese poder se convierta en arbitrario y despótico. Pero Leibniz está cansado, viejo y enfermo (morirá un mes después de escribir su última carta a Saint-Pierre); ha gastado demasiadas energías en intentar conseguir la reunión de las iglesias para seguir luchando en un tipo de empresa que es como clamar en el desierto; ahora le toca a Saint-Pierre emplearse en la tarea, pues él quiere dedicarse a culminar su obra filosófica ${ }^{34}$ (le pesa el compromiso adquirido con la casa Brunswick de escribir la historia de su linaje), convencido en el fondo de que sólo en la universalización de una concepción filosófica puede descansar la expansión "cosmopolita" 35 de la idea de paz.

${ }^{32}$ Carta de Leibniz al Abbé de Saint-Pierre, 4 de abril 1715, "Voprosy filosofii”" 18 (1964), pp. 123 124. En la carta a Grimarest del 4 de Junio de 1712 Leibniz había presentado la cuestión mucho más drásticamente: "Sería preciso que todos esos señores entregasen una caución burguesa, o depositasen en el banco del tribunal: un rey de Francia, por ejemplo, cien millones de escudos, y un rey de gran Bretaña, una cantidad proporcional, a fin de que las sentencias del tribunal pudieran ser ejecutadas sobre su dinero, en caso de que se mostrasen refractarios".

33 Cf. Txetxu Ausín, Los límites del principio de precaución en la praxis ético-politica contemporánea (FFI 2011-24414: http://kontuz.weebly.com/)

34 "Tengo tanta tarea por delante, señor, que me es moralmente imposible ahora acometer nuevos trabajos, aparte de que usted no tiene ninguna necesidad de mi ayuda. Si vuestra reputación y vuestras obras no pueden superar las dificultades, las de otro lo harían menos todavía...", carta del 4 de abril de 1715, loc. cit., p. 124.

35 Bien entendido que Leibniz mismo no llegará a emplear esta expresión, como bien ha subrayado A. Robinet en sus trabajos. Cf. asimismo L. Basso, Individuo e comunità nella filosofia politica di G.W. Leibniz, Sovera Mannelli, Rubbetino, 2005, passim. 


\section{El federalismo como base de un nacionalismo no absolutista: la balanza de Europa.}

Para entender mejor la relevancia de la propuesta leibniziana, recordemos someramente la situación política de Europa tras la Guerra de los Treinta Años: la antigua unidad de occidente se había desintegrado por completo y Centroeuropa estaba devastada; con la Paz de Westfalia (1648) se daba por concluida la era de los principios confesionales en la política y, con ello, la hegemonía de la cristiandad. Leibniz se enfrenta con la realidad de un Kaiser debilitado, de una Alemania dividida en innumerables estados soberanos, y de una Francia poderosa que quiere expandir su imperialismo. Por una parte, tiene nostalgia de una unidad interna de Europa, con todas sus premisas religiosas; por otra parte, estaba convencido de que ya no se podía restaurar el imperio como "Corpus Christianum" en sentido medieval. Por eso, dedica gran parte de sus escritos políticos a estudiar la manera de consolidar el Imperio alemán como Estado-nación, a la par que se opone a la política absolutista de Luis XIV, pues la constitución de naciones fuertes contribuye a instaurar un equilibrio en Europa $^{36}$. Cuando Leibniz habla en sus escritos del Sacrum Imperium se está refiriendo a la nación alemana (Heilige Römische Reich Deutscher Nation) que empieza a constituirse después de la paz de Westfalia, un Imperio que debe seguir la máxima de "multiplicidad en la unidad" como principio constitucional del federalismo: "el imperio consiste en la reunión de estados federados" El Imperio es una "familia de estados", un "sistema de estados individuales confederados", cuya forma externa se basa en poder ofrecer una garantía de seguridad. Ocasionalmente hablará Leibniz también de una "comunidad de estados" que está sujeta a la soberanía de un Estado general ${ }^{38}$. Ya en Bedencken welchergestalt Securitas publica interna et externa und Status praesens im Reich iezigen Umbständen nach auf festen Fuß zu stellen (1670), que puede considerarse como su primer gran memorándum político (redactado en Mainz por encargo de Boineburg), aparece claro el interés leibniziano por introducir en el Imperio las reformas necesarias para contribuir a su seguridad y a la consolidación de un sistema constitucional; allí propone Leibniz especialmente una "nueva alianza de estados alemanes" (neue Alliance Teutscher Stände) ${ }^{39}$,

\footnotetext{
${ }^{36}$ Los esfuerzos leibnizianos por conseguir la reunión de las diversas confesiones protestantes perseguían reforzar la alianza de los estados federales y contribuir con ello a una balanza política en Europa. Cf. G. Utermöhlen, Vereinigung der Konfessionen [en A. Heinekamp, ed.: Leibniz und Europa, Hannover, Schlüter, 1994], pp. 95-114.

${ }^{37}$ Elementa juris naturalis, „Untersuchungen“(1669-1670) [en Gottfried Wilhelm Leibniz: Sämtliche Schriften und Briefe, Deutsche Akademie der Wissenschaften, 1923-1950, VI, 1, 446]. Citaré esta edición con la sigla "A".

${ }^{38}$ Cf. H-P. Schneider, Fürstenstaat, Reich und Europa. Leibniz zwischen dynastischen Interessen, föderativer Reichsidee und Europäischer Union, [en A. Heinekamp, ed.: Leibniz und Europa, loc. cit.], p. 144.

${ }^{39}$ A IV, 1, 140. Cf. Ibid., 137-140. Cf. también C. Roldán, Leibniz und die Europaidee "Jahrbuch für 
con la finalidad de originar tal unidad y cohesión en el Imperio que le permita resistir a las hostilidades de Francia; se trata, pues, de una "unidad defensiva", donde cada estado conserva su autonomía, teniendo en común un "Consejo federal" (Bundesrat), unos "Fondos federales" (Bundeskasse) y un "Ejército federal" de 20.000 soldados que defendieran la marca del Rhin ${ }^{40}$. De esta manera, puede decirse que el Estado ya no es para Leibniz, como lo era para Grocio y la tradición, sólo una "comunidad natural" (como el matrimonio o la familia) que persigue el bienestar de sus súbditos, sino también una "unidad administrativa" que tiene como meta la seguridad de los ciudadanos ante una amenaza externa; esta finalidad defensiva (cohabitatio securitatis causa) y la unidad en aras de una administración común (administratio comunis) convierten a Leibniz en uno de los pioneros del Estado moderno.

Leibniz propone una liga federal de principados, conservando cada uno su soberanía y presididos por un Kaiser que se renovaría rotativamente y tendría que someterse a un Senado (concilium perpetuum) que ostentaría las funciones de árbitro para evitar una forma de gobierno absolutista ${ }^{41}$. Pues el monarca no es el Estado ${ }^{42}$, sino un miembro del mismo, con el deber de preocuparse por el bienestar del pueblo. Y esta forma federal de Estado le parece que reporta una unidad política necesaria para oponerse a otros poderes políticos, a la vez que respeta la libertad y pluralidad de los Estados que tienen a su alcance el control de la "administración" imperial. En cualquier caso, se trata de un federalismo nacional que no le parece trasladable a una confederación europea que persiguiese instaurar el orden o paz perpetuos sobre esa base. Como escribe refiriéndose al proyecto de Saint-Pierre, hay diferencias sustanciales entre la federación del Imperio y la que el abad propone entre los Estados europeos, pues en esta última los súbditos no podrían interponer demandas contra sus príncipes o magistrados $\mathrm{y}$, sobre todo, porque los diputados que formaran parte del utópico senado cristiano tendrían que seguir las instrucciones de sus

Europäische Geschichte" 2 (2001), pp. 261-272 y Leibniz' Concept of Europe between Nationalism and Universalism [en A. Mogach y M. Buhr, eds.: Reason, Universality and History; Perspectives on the European intellectual Legacy, New York/Ottawa/Toronto, Legas, 2004], pp. 147-162.

${ }^{40}$ Aquí asistimos a la propuesta leibniziana de creación de un ejército permanente (miles perpetuus) que estaría en franco desacuerdo con la postura de Kant (3. artículo preliminar para la paz perpetua de los Estados: "Los ejércitos permanentes deben desaparecer totalmente con el tiempo", Ak. VIII, 345). En Geschwinden Kriegsverfassung (1688) vuelve Leibniz sobre el tema, subrayando el deber patriótico de defensa del Imperio.

${ }^{41}$ Cf. Caesarini Fürstenerii de Jure Suprematus ac legationis Principium Germaniae (1677), A IV, 2 , 3ss. Cf. A. Robinet, G.W.Leibniz. Le meilleur des mondes par la balance de l'Europe, PUF, Paris 1994, 239-240.

${ }^{42}$ Recuerda el lema de Luis XIV: "L'Estat c'est moi”. Por encima de la autoridad del monarca está la del Derecho, pues las leyes vigentes que un príncipe o monarca promulgan no son el Derecho mismo; una premisa que hace del Imperio un Estado moderno es su constitución como "unidad de derecho" (no sólo "unidad política" o "territorial"); cf. Codex Juris gentium diplomaticus (1693) o Mantissa (1700). Cf. Q. Racionero, Racionalidad cientifica y racionalidad politica en Leibniz [en E. Olaso, ed.: Leibniz: Sobre los principios, Buenos Aires, Latinoamericana de Filosofía, 1992], pp. 83-109. 
principados respectivos ${ }^{43}$, esto es, de un lado se pierde de vista la salvaguarda de la libertad, felicidad y justicia de los ciudadanos, y de otro se favorece que cada Estado abogue por sus propios intereses (económicos, sin ir más lejos), perdiendo de vista el objetivo pacífico común. Una federación europea no sabría, en su opinión, conculcar la idea de política internacional entendida como "lucha por el poder", que por sí misma hace imposible la realización de una paz perpetua.

Un Estado federal conseguiría eludir el absolutismo ${ }^{44}$ a la vez que contribuiría a constituir una nación fuerte, necesaria para mantener el equilibrio europeo, haciendo frente a sus dos agresores potenciales: la Francia de Luis XIV por el oeste y el Imperio Otomano por el sudeste. Se trata, pues, de un federalismo nacional "para la guerra"; el potencial militar de los estados y con ello la capacidad de hacer la guerra garantizaba el equilibrio europeo ${ }^{45}$. Cada nación buscaría su bienestar en un estado de paz que sería una tensión permanente no violenta que favorecería el florecimiento de cada Estado en un dinamismo que exigiría de todos constantes reajustes; el peligro vendría de un desarrollo excesivo de una de las fuerzas, lo que haría inclinarse la balanza hacia un lado, constriñendo a la otra bajo su ley; de ahí el peligro, ligado al absolutismo, de una "paz perpetua ludovica", que significaría la supresión de uno de los platillos de la balanza ${ }^{46}$. La paz es así entendida de forma dinámica, como alternancia equilibrada de potencias, como posibilidad de guerra si se violan los pactos; guerras "hermosas" 47 que tendrían como finalidad el restablecimiento de una paz justa y que significarían la continuación de la política con otros medios. No puede, por tanto, conseguirse la paz a través de confederaciones entre Estados que sólo pueden suscribir alianzas temporales para defenderse de un enemigo común; en el terreno de los intereses políticos la paz es siempre de naturaleza temporal ${ }^{48}$ y por este motivo ha de contar el

${ }^{43}$ Cf. Observations, loc. cit., F. de C., 333-336. Para Leibniz, la independencia de los magistrados del Imperio reside en su libertad de conciencia o de juzgar, que es signo de la libertad de filosofar (333). Sin olvidar el detalle histórico, dice Leibniz, de que la "unión alemana" no comenzó por ningún tratado (334).

${ }^{44}$ Aunque podría estar de acuerdo con Hobbes en que la naturaleza humana tiende a un conflicto de intereses ("la guerra de todos contra todos"), su confianza en la razón le impide creer que la única forma de dominar esa naturaleza sea por medio de un omnipotente Estado-monstruo (el Leviatán). Su doctrina del Derecho es precisamente el intento de encontrar el equilibrio entre derecho (que no hay que confundir con leyes) y poder.

45 Según R. Aron, la "paz de equilibrio" se distinguiría de la de "hegemonía” y de "imperio", en que las fuerzas políticas se encontrarían en relación de igualdad; cf. Paix et guerre entre las nations, Paris, Calmann-Lévy, 1962, p. 166.

${ }^{46}$ Cf. A. Robinet, op. cit., p. 236. En este sentido, critica la alianza de las casas de Francia y España, y de un eventual acceso al trono de Inglaterra de un Borbón (cf. F. de C., p. 175 ss.). Por eso recomienda al Kaiser que tome parte en la guerra de sucesión española, o que apoye al zar en la guerra del norte.

47 “Je ne voudrais pas...une trop profonde paix. J'ay quelque sujet particulier de desirer qu'il y ait de belles guerres et non pas de desordres", carta de Leibniz a Sofía, 14 enero 1699 [en O. Klopp, ed.: Die Werke von Leibniz, Hannover, Klindworth, 1877, VIII, 109]; cursivas mías.

48 "Friedensvertrag". Basta con hojear los índices de la edición de la Academia para ver que "paz" lleva siempre para Leibniz adjetivo: “de Aachen”, "de Nimwegen”, "de Ryswick", "de Utrecht”, etc. 
derecho internacional con la necesidad de la guerra. Hay una infracción de la armonía superior a la de la guerra y es la de la injusticia.

Desde un punto de vista político no puede soñarse, pues, según Leibniz, con la instauración de una paz perpetua al margen de la situación histórica. Por eso le parece utópica la postura de Saint-Pierre, equiparándola a una novela del siglo de oro en su pretensión de resucitar el Sacro Imperio Romano ${ }^{49}$. Aunque la paz sea deseable como "orden mundial", no puede olvidarse que la balanza de la historia oscila entre la guerra y la paz, esto es, entre diversas guerras y tratados de paz. El conocimiento de la historia y de la psicología de los soberanos conduce a un realismo político que no va más allá de la pretensión de un equilibrio de poder entre las naciones, cuya salvaguarda en el derecho internacional sigue siendo la posibilidad de la guerra justa ${ }^{50}$, entendida como un mal necesario que un hombre de bien sólo puede recomendar como medida extrema ${ }^{51}$; pues no hay posibilidad de paz duradera cuando los tratados de paz no velan por la integridad y dignidad de las naciones, o cuando una potencia da rienda suelta a su ambición desorbitada de expansión territorial, a costa de otras ${ }^{52}$.

La paz es, pues, entendida por Leibniz en el ámbito político como un concepto negativo: la no-guerra (pax absentia belli) ${ }^{53}$, reducida a la contingencia de los tratados (pactum pacis) y alcanzable sólo por medio de un orden de derecho internacional (ius gentium) que confiere legitimidad a la guerra justa (bellum iustum) como garantía de su realización. Sería ingenuo pensar que la paz perpetua esté entre los intereses políticos de los poderosos

${ }^{49}$ Cf. carta Leibniz a Grimarest del 4 de junio de 1712. En este sentido escribe Leibniz irónicamente a Conrad Widou el 30 de octubre de 1716: "Si el señor abad de Saint-Pierre pudiera volver a todos Romanos y hacerles creer en la infalibilidad del Papa, no haría falta ningún otro imperio que el del Vicario de Jesucristo". Cf. al respecto E. Goumy, Etude sur la vie et les écrits de l'Abbé de Saint-Pierre, Genève, Slatkine Reprints, 1971, 36-37.

50 "La juste guerre est celle que l'homme juste doit entreprendre pour retablir l'equilibre de la balance", A. Robinet, op . cit, 245. Por lo que respecta al concepto de guerra justa, Leibniz es deudor de Hugo Grocio, en cuya obra De iure belli ac pacis (1625) aparece tratado el tema de forma sistemática, mientras que Leibniz lo hace al hilo de los conflictos de la época; cf. A. Truyol y Serra, Die Lehre von gerechten Krieg bei Grotius und Leibniz und ihre Bedeutung für die Gegenwart, "Studia Leibnitiana" XVI/1 (1984), 60-72. En las Raisons touchant la guerre ou l'accomodement avec la France (1684) aparece un análisis pormenorizado de las condiciones que debe reunir una guerra justa para oponerse a las ambiciones del poder absoluto; cf. A IV, 2, 503 y ss.

${ }^{51}$ «Tout homme de bien demeure d'accord qu'on ne doit jamais faire la guerre que lorsqu'il est fort nécessaire», Réflexions sur la déclaration de la guerre, A IV, 3, 110. Cf. al respecto Ibid., 130.

${ }^{52}$ Esta es la melodía de fondo de Mars christianissimus (1683), dirigido contra el expansionismo francés. En el Manifeste contenant les droits de Charles III, roi d'Espagne, et les justes motifs de son expédition (1703) se justifica la intervención bélica antes que sufrir una "paz injusta". Sobre diversos ejemplos en que se violan la integridad y dignidad de las naciones, sobre todo por parte de Francia, cfr. A. Robinet, op. cit., pp. 238-242.

${ }^{53}$ Sobre este concepto negativo de paz ha insistido uno de los más prolíficos investigadores de la paz contemporáneos, Johann Galtung, Violence, Peace and Peace Research [en J. Galtung, ed.: Peace: Research, Education, Action, Essays in Peace Research, vol. I, Copenhague, Christian Ejlers, 1975], pp. 109-134. 
y que quieran formar confederaciones "para la paz"; más bien se reúnen en alianzas transitorias "para la guerra", es decir, para defenderse de un enemigo común. Por eso, para poder instaurar una paz duradera hay que trascender el nivel político y situarse en un campo donde se carezca de intereses o, mejor dicho, éstos sean universalizables.

\section{El papel pacificador de la ciencia: Leibniz fundador de Academias}

La constitución de una Sociedad internacional de sabios subyace a todos los planes leibnizianos de fundación de Academias $^{54}$. Hombres bienintencionados que guiados por la razón tiendan a conseguir el provecho de todo el género humano por encima de las cortas miras nacionales ${ }^{55}$. Sociedades que no se queden en los fragmentos provisionales que suponen las academias nacionales, sino que promuevan una Academia europea más vasta, una especie de federación internacional de sabios $^{56}$ cuya finalidad es extenderse al universo entero.

Leibniz presentó proyectos para fundar Academias en varias cortes importantes de Europa: Berlín, Viena, Dresde y San Petesburgo, de los cuales sólo consiguió realizar el de la Academia de Ciencias de Berlín (gracias al apoyo de Sofía Carlota), aunque el de San Petesburgo se realizara poco después de su muerte ${ }^{57}$. Prefiere llamar a estas instituciones Sociedades (para distinguirlas de las Universidades, denominadas a veces en aquella época Academias), recalcando su carácter liberal y tolerante, acogiendo a sus miembros sin ninguna distinción de nacionalidad y religión. Al igual que en las instituciones anteriores de Francia e Inglaterra, la Académie Française (1635) y la Royal Society (1662), Leibniz propone como objeto de las Sociedades alemanas: cultivar las ciencias, recoger observaciones (sobre todo médicas), trazar estadísticas demográficas, recoger información sobre las obras publicadas, facilitar reseñas o subvencionar la publicación de enciclopedias; pero a diferencia de sus vecinos franceses e

\footnotetext{
${ }^{54}$ Cf. H. Poser, Die Leibnizschen Akademiepläne als Element der Einheit Europas [en Concha Roldan, ed.: Leibniz und Europa, St. Leib. SH (en prensa)].

${ }^{55}$ No en vano uno de sus proyectos para la fundación de una sociedad de sabios lleva por título Memoria para personas ilustradas de buena intención (1692), Klopp X, 7-36. (ed. cast. de J. de Salas, Memoria para personas ilustradas y de buena intención [en Leibniz. Escritos de filosofia jurídica y política, Madrid, Biblioteca Nueva, 2001], pp. 375-392).

${ }^{56}$ Cf. carta a Placcius de 1696 [en G. E. Guhrauer, ed.: Leibniz's deutsche Schriften, Berlin, 1834-40, II, 181). Cf. C. Roldán, Theoria cum Praxi: the Republic of Letters in Leibniz, "Studia Leibnitiana" SH 37 (2010), pp. 71-81.

${ }^{57}$ El borrador de la fundación de la Academia rusa preparado por Pedro el Grande el 28 de Enero de 1724, se basa en las propuestas de Leibniz; cfr. L. Richter, Leibniz und sein Russlandbild, Berlin, Akad.-Vlg., 1946, 127ss. Harnack describe con detalle la historia de los planes de Leibniz sobre la Academia en Geschichte der Preussischen akademie der Wissenschaften (1900). También resulta productivo consultar al respecto L. Couturat Sur Leibniz fondateur d'Academiés [en L. Couturat, La logique de Leibniz, Paris, Alcan, 1901], pp. 501-528.
} 
ingleses, Leibniz no se conforma con un órgano para canalizar los resultados de las investigaciones, sino que tiene sus ojos puestos en la utilidad pública (commune bonum) que la colaboración de los científicos puede promover, llegando a convertirse en una verdadera república de sabios; en este sentido, escribe a Pedro el Grande ${ }^{58}$.

La idea de una cooperación científica de sabios que contribuyese a mejorar por medio del desarrollo las condiciones de vida de la humanidad, se encontraba ya en las reflexiones de Francis Bacon (1561-1626); de él hereda Leibniz el deseo por una comunicación abierta de los resultados científicos y la creación de contactos internacionales como condiciones de la gran renovación científica. Pero también podemos encontrar entre sus antecesores a Johann Amos Comenius (1592-1670), quien diseñó una doctrina de sabiduría universal, la Pansophia ${ }^{59}$, donde propugnaba la armonía de todas las cosas desde su fundamentación religiosa; para Leibniz, igual que para Comenius, la ciencia está ontológicamente cimentada en la creencia en una armonía universal, por medio de la cual sería posible construir el mundo terrenal (reino de la naturaleza) siguiendo el modelo de la armonía divina (reino de la gracia).

El conocimiento es el puente que une a los hombres con Dios. Pero la aspiración a conseguir conocimientos científicos teóricos tiene que estar al mismo tiempo ligada a un aprovechamiento práctico ${ }^{60}$, para alcanzar la felicidad del género humano. De ahí que la tarea moral de las personas que detentan posición, fortuna y prestigio sea impulsar la fundación de sociedades científicas $^{61}$. "Harían falta no sólo personas elegidas con inteligencia y empeño -escribe Leibniz-, sino también muy desinteresadas, con más ilusión en la gloria y satisfacción de lograr el bien general que en amasar grandes riquezas" ${ }^{2}$. La gloria es lo que ofrece a aquellos príncipes de espíritu elevado que se interesen en su empresa, una gloria verdadera conquistada por promover la paz universal por la difusión de la ciencia, por contribuir al bienestar del género humano superando las disensiones, "pues no sólo la extensión de los territorios es lo que

${ }^{58}$ CF. H. Breger Die Wissenschaften als Kennzeichen und verbindendes Band der europäischen Völker [in A. Heinekamp, ed.: Leibniz und Europa, loc. cit.], p. 75. El artículo muestra de forma interesante el interés leibniziano por el progreso científico y su relación con una cooperación internacional de sabios.

${ }^{59}$ En su escrito redactado en Londres en 1641, Via lucis, hace Comenio determinadas propuestas de organización exterior de las ciencias que deben conducir a la pansofía. Sobre influencias de Bacon y Comenio, cf. W. Totok, Leibniz als Wissenschaftorganisator [in A. Heinekamp ed.: Leibniz und Europa, loc. cit.], pp. 116-119.

60 "La separación de la teoría y de la práctica hace a la ciencia estéril y a la práctica imperfecta", Memoria para personas ilustradas de buena intención, ed. de J. de Salas, p. 387.

${ }^{61} \mathrm{Cf}$. Memoria para personas ilustradas de buena intención, Klopp X, \&\& 5-6, ed. cast. de J. de Salas, p. 376. En Consultatio de naturae cognitione (1679) proporciona una lista de cincuenta personas sabias y juiciosas -en el ámbito alemán- con las que habría que ponerse en contacto, A IV, 3, 878; ed. cast. de J. de Salas, pp.366-67.

${ }^{62}$ Memoria para personas ilustradas..., ed. de J. de Salas, p. 387. “Aun no siendo fácil -continúa en el mismo lugar-, se encuentra bastante gente de esta clase en el mundo". 
hace a un príncipe rico, sino también la cultura e industria de sus habitantes"63. Se trata, pues, de mejorar la voluntad de los hombres, algo que según Leibniz se consigue iluminando su entendimiento, esto es, mediante la reforma de la educación, que debe consistir en hacer agradable la virtud y en convertirla en una especie de naturaleza, entendiendo que fortalecer la voluntad por el ejercicio de las virtudes no es algo diferente de habituarse a actuar según la razón ${ }^{64}$.

En el apartado segundo veíamos como Leibniz criticaba a Saint-Pierre por no solucionar el problema fundamental para acceder a la consecución de una paz perpetua, esto es, hacer que los hombres quisieran la paz. Ahora vemos como Leibniz pretende mejorar la voluntad de los hombres por medio de la instauración de Sociedades científicas que contribuyan al progreso de la razón a la vez que difunden las ciencias y las artes. Se trata de que la difusión de la cultura contrarreste la barbarie, de ir ganando adeptos de forma que cuando más de la mitad de la humanidad se dé cuenta de lo que puede progresar el género humano en paz, llegue a desestimarse el valor de la guerra: "El género humano llegará a ser culto en todas las partes del mundo, sólo cuando nuestra Sociedad domine más de la mitad de la humanidad; entonces ejercerá dicha sociedad de árbitro en las guerras y garantizará la seguridad universal sin el empleo de la fuerza injusta. ¡Radiante y favorable día para la humanidad cuando esto acontezca!" ${ }^{65}$. Para el joven escritor de la Societas philadelphica, la única forma de conseguir a largo plazo la paz perpetua es hacer que todos los puestos de importancia en la vida pública se encuentren en manos de miembros de la sociedad, a modo de reyes-filósofos platónicos; pero a pesar de tratarse de una sociedad de carácter internacional, está concebida según el modelo de las utopías clásicas, en un lugar libre (que podría ser Holanda), independiente tanto del Emperador, como del Papa y del Rey francés.

Con los años los proyectos leibnizianos de expansión de la ciencia se van tornando realistas, pero nunca abandonará por completo su optimismo ilustrado en la perfectibilidad y el progreso del género humano, ni la fe en el poder de la razón. La universalidad de la ciencia debía infundir en los pueblos un sentimiento supranacional; tras un proceso de "educación de la humanidad", los poderosos gobernarían con sabiduría y reinaría por todas partes un estado

\footnotetext{
${ }^{63}$ Ibid., p. 386. "El rey de Francia -continúa un poco más adelante-, después de la Paz de los Pirineos, parecía haber tomado el verdadero camino de la gloria: se dedicaba a hacer prosperar sus estados;...atrajo a su reino y se ganó por sus favores a los más grandes genios de Europa;...hizo cultivar las ciencias y las bellas artes,...; mediante los grandes descubrimientos que se llevaron a cabo bajo sus auspicios, el rey contribuyó al aumento de la felicidad de los hombres. De esta suerte se puede afirmar que si el rey hubiera seguido así desde esta época, se habría progresado mucho en treinta años... Pero la desdichada ambición de conquistar una falsa gloria mediante la guerra, de engrandecer sus estados mediante conquistas, ha puesto término a esta esperanza", ibid. pp. 388-89.

${ }^{64}$ Ibid. p. 378.

${ }^{65}$ Societas philadelphica (1669), A IV, 1, 556.
} 
de libertad y felicidad (perfectio mentium). La ciencia debía ser un vínculo unificador en una Europa plagada de disarmonías políticas y rivalidades de poder. Una ciencia que debe ser entendida como filosofía que persigue como fin fundamental el perfeccionamiento de todos los hombres, la armonización de todos los pensamientos en un reino divino omniabarcante, que conduce a todos los seres humanos a una sociedad con Dios. En este contexto, la instauración de la paz universal (que aparece como imposible inmediatamente en el ámbito político) se convierte en una de las condiciones para que se cumplan estas metas científico-filosóficas, pero no debe detener su tarea por la guerra que nunca puede amenazar su paz interior ${ }^{66}$; ni siquiera debe renunciar a participar en la guerra si la razón así lo aconseja, pues la armonía cuenta en su desarrollo con las disonancias ${ }^{67}$, lo mismo que el progreso no se ve interrumpido por los retrocesos aparentes en la historia ${ }^{68}$. El filósofo no cuenta con ningún otro poder que la fuerza de su razón para enseñar a los hombres el camino de la paz; una razón que se encuentra por encima de los intereses políticos y económicos y que puede por ello promover una paz entre las naciones.

En un momento de crisis y desencanto, en el que ni los políticos de oficio ni los príncipes y monarcas aportan ninguna solución, Leibniz espera la salvación (también política) de la mano de los filósofos, de la "república de sabios" que deben encargarse de armonizar teoría y práctica, poder y razón. Algunos autores han subrayado que la verdadera intención de Leibniz no era otra que la instauración de una República cristiana universal ${ }^{69}$, pero yo no comparto esa interpretación, no sólo porque sería incompatible con los planteamientos políticos perspectivistas y tolerantes de Leibniz $^{70}$, sino porque esto sería contradictorio con su misma filosofía, enraizada en el concepto de "armonía universal" que hace pie en la multiplicidad y diversidad de lo existente. Leibniz, a diferencia de un Comenius, para quien la ciencia surgiría como el principal instrumento para expandir el cristianismo (propagatio verae fidei per scientias), ha dado ya en sus reflexiones un paso decisivo en el camino de la modernidad $^{71}$, enmarcándose en las líneas clave de la ética y política ilustradas,

\footnotetext{
${ }^{66}$ Así, escribe a Foucher el 16 de abril de 1695: "Por su última carta, que ya hace tiempo que recibí, entiendo que quiere usted interrumpir nuestra correspondencia a causa de la guerra. No querría causarle ninguna incomodidad por ello. A pesar de todo, no creo que esté en su intención renunciar a ella por completo, pues una gran cantidad de hombres me escriben a pesar de la guerra, que no afecta a la filosofia"; las cursivas son mías.

${ }^{67}$ Cf. por ej. Confessio philosophi, A VI, 3, 122 y Resumen de Teodicea (1710), GP VI, 384.

68 "Si se recula siempre es para saltar mejor", De rerum originatione radicali, GP VII, 308. Cf. carta a Bourguet del 5 de agosto de 1715, GP III, 578.

${ }^{69}$ Cf. Frank E. Manuel y Fritzie P. Manuel, Leibniz, o el canto de cisne de la República cristiana [en Frank E. Manuel y Fritzie P. Manuel, El pensamiento utópico en el mundo occidental, Madrid, Taurus, 1984, vol. II], pp. 266-292.

${ }^{70} \mathrm{Cf}$. C. Roldán, La idea de tolerancia en Leibniz [en $\mathrm{M}^{\mathrm{a}}$. J. Villaverde y Ch. Laursen, eds.: Forjadores de la tolerancia. Claroscuros en el pensamiento europeo de los siglos XVII y XVIII, Madrid, Tecnos, 2011], pp. 162-180.

${ }^{71}$ Esta sería a mi entender la tesis defendida también por J.I. Israel, Radical Enlightenment: Philosophy and the Making of Modernity 1650-1750, Nueva York, Oxford University Press, 2002, quien pone una especial atención en Spinoza.
} 
que en lo que a las reflexiones de este trabajo competen serían la secularización -o emancipación ética respecto de la religión-y un planteamiento político federalista.

\section{A modo de conclusión}

Para Leibniz la paz perpetua no puede resultar inmediatamente del establecimiento de confederaciones políticas (o económicas) entre diversos Estados, pues entraría en contradicción con los conflictos internacionales de intereses no siempre solventables de manera pacífica. Sin embargo, existe otro tipo de confederaciones a las que Leibniz confiere la tarea de instaurar mediatamente la paz universal: las sociedades científicas, en cuanto que sus miembros, al servicio de intereses universales que trascienden las fronteras, influyan sobre los soberanos haciendo que el gobierno de la recta razón se anteponga a las ambiciones del poder. De ahí que "la mejor forma de servir a Dios sea la de la actividad política"72; esta convicción es la que sustenta su famoso lema Theoria cum praxi que acompaña a los planes leibnizianos para la fundación de Academias (que él prefiere denominar Sociedades) a lo largo de su vida ${ }^{73}$, proyectos que podemos inscribir sin riesgo de error en el programa ilustrado para la "educación del género humano". Las actividades políticas de Leibniz estarían, desde este supuesto, al servicio de un proyecto ético más amplio que perseguía la liberación de los seres humanos y la consecución de su felicidad y paz universales por medio de los avances en el conocimiento. Práctica política al servicio de una teoría ética en la que subyace una concepción filosófica de la historia lineal, fundada en la confianza en la perfectibilidad de la razón humana que conduciría al progreso moral del género humano; el deber de cada individuo sería poner su razón al servicio de la humanidad esforzándose por construir el mejor de los futuros posibles ${ }^{74}$.

Desde un punto de vista político, el diplomático Leibniz tiene que defender los intereses de su príncipe y velar por un imperio alemán fuerte que resista los envites franceses, pero por encima de estos intereses particulares están los intereses universales de la razón que tiende a la idea de una "comunidad cultural europea" armónica que por medio de la ciencia se extienda por el puente de Rusia al corazón de Asia y al resto de los países extranjeros. Al contrario que los

${ }^{72}$ Grundriß eines Bedenckens von Aufrichtung einer Sozietät in Teutschland zu auffnehmen der Künste und Wissenschaften (1671), A IV, 1, 535.

${ }^{73}$ Desde los primeros ensayos de 1669 hasta el último de 1715. En vida de Leibniz sólo se realizó el Plan para la fundación de una Academia en Berlín, gracias al impulso de la reina Sofía Carlota; e inmediatamente después de su muerte se llevó a cabo el que había concebido para el Zar Pedro el Grande.

${ }^{74}$ La idea de progreso moral, que combate cualquier interpretación estática del "mejor de los mundos posibles", se extiende desde algunos de sus primeros escritos -como la Confessio philosophi de 1673- hasta formulaciones de la última década de su vida -como la Teodicea. Cfr. al respecto mi artículo El principio de perfección y la idea de progreso moral en Leibniz, "Il cannocchiale" 1 (1992), pp. 25-44. 
Estados políticos, cuyos intereses enfrentados conducen al conflicto, el Reino de la ciencia no conoce fronteras y necesita de la cooperación para aumentar su poder, colaborando en una obra colectiva e impersonal que persigue como única meta el progreso perpetuo de la civilización, de ahí que no sea importante que un descubrimiento se realice en una u otra nación, sino que contribuya al bien de la humanidad ${ }^{75}$.

El camino paulatino hacia una paz perpetua pasa, pues, para Leibniz por la fundación de una "Sociedad de espíritus" ", esto es, de seres racionales que sitúen los intereses comunes de la humanidad por encima de sus respectivos intereses patrióticos. No se trata de un concepto diferente al conocido "Reino de la Gracia"77, que aparece en alguno de sus últimos y más conocidos escritos metafísicos, y es precisamente la prueba de que todas las disciplinas a las que Leibniz dedica sus esfuerzos están profundamente interrelacionadas. Esta Sociedad moral no se encuentra situada en un limbo abstracto, ni en una esfera trascendental o meramente formal, sino que recibe su contenido de la historia concreta, de su propuesta de construir una Sociedad científica internacional, fundamentada en la fuerza de la razón y que consiga paulatinamente, por el influjo de sus miembros, poner el poder al servicio de la paz. La ciencia sería la encargada de acabar con la fragmentación de la humanidad al servir de vehículo de pacificación entre las distintas culturas que reconocerían a su paso su origen común y su común esencia racional. Por encima de cada nación está la humanidad, la armonía de las naciones, la comunidad cultural de Europa y la posibilidad de una unidad cosmopolita futura. Tal como escribe en un poema a Mlle. d'Scudery: "Se sea europeo, chino, o de cualquier parte del mundo, la magnanimidad no puede prestar atención más que al ser humano"78.

\footnotetext{
75 En este sentido escribe a Des Billetes el 21 de octubre de 1697 (GP VII, 456): "Pourveu qu'il se fasse quelque chose de consequent, je suis indifferent que cela se fasse en Allemagne ou en France, car je souhaitte le bien du genre humain".

${ }^{76}$ Recordemos que Leibniz denomina “espíritus" a aquéllos seres vivos que poseen capacidad racional, para distinguirlos de las demás "almas" que sólo cuentan con espontaneidad.

77 Cf. por ej., Principios de la Naturaleza y de la Gracia \&15 (GP VI, 605), Monadología \&\& 84 y 85 (GP VI, 621) y Teodicea \& 118 (GP VI, 168).

${ }^{78}$ Hannover, 25 de noviembre de 1697 (A I, 14, 752). Las cursivas son mías.
} 


\section{Referencias bibliográficas}

\section{Fuentes primarias}

Kant, I., Metaphysik der Sitten, Ak. VI, (trad. castellana de A. Cortina y J. Conill, Madrid, Tecnos, 1989).

—_, Zum ewigen Frieden, Ak. VIII, (trad. castellana de J. Abellán, Madrid, Tecnos, 1985).

Kortholt, Recueil de diverses pièces, Hamburgo, Vandenhoeck, 1734.

Leibniz, Observations sur le projet d'une paix perpétuelle de M. L'Abbé de Saint-

Pierre [en A. Foucher de Careil, ed.: Euvres de Leibniz, París, Firmin Didot, 1859-1875, Tome 4].

— Die Philosophischen Schriften von Gottfried Wilhelm Leibniz, ed. de C.I. Gerhardt, Berlin, Weidman, 1875-1890.

- Sämtliche Schriften und Briefe, hg. von der Akademie der Wissenschaften (Akademieausgabe), Reihe I-VII, Darmstadt, später Leipzig, zuletzt Berlin, $1923 \mathrm{ff}$.

— Escritos de filosofía jurídica y política, ed. y trad. de Jaime de Salas, Madrid, Biblioteca Nueva, 2001.

—, Leibniz's Deutsche Schriften, ed., de G. E. Guhrauer, Berlin, 1834-40

—, Correspondance G.W. Leibniz - Ch.-I. Castel de Saint-Pierre, ed. de A. Robinet, Paris, Centre de philosophie du droit, 1995.

Saint-Pierre (Castel de Saint Pierre, Charles-Irénée), abad de, Projet pour rendre la paix perpétuelle en Europe, ed. de Simone Goyard-Fabre, París, Fayard, 1986.

_- Discours sur la Polysynodie où l'on demontre que la Polysynodie, ou la pluralité des Conseils, est la forme de Ministère la plus avantageuse pour un roi, \& pour son Royaume, Amsterdam, 1718.

Voltaire, Rescripto del Emperador de la China con motivo del proyecto de paz de perpetua (1761) [en Voltaire: Opúsculos satíricos y filosóficos, Alfaguara, Madrid, 1978].

Anti-Maquiavelo o Refutación del Príncipe de Maquiavelo, ed. de Roberto R. Aramayo, Madrid, Centro de Estudios Constitucionales, 1995.

J.J. Rousseau, Resumen del Proyecto de Saint-Pierre, trad. de J. Rubio Carracedo, "Philosophica malacitana", 6 (1993).

, Écrits sur L'Abbé de Saint-Pierre (1756-59) [en J. J. Rousseau, Oeuvres Completes. III. Écrits politiques, Paris, Bibliothèque de la Pléiade, 1964].

\section{Estudios}

Aramayo, R. R., “La balance d'Europe: Saint-Pierre chez Frédéric II, Rousseau, Leibnizet Kant" [en H.Poser, ed.: Nihilsine ratione. VII. Internationaler Leibniz-Kongress, Berlin, Technische Universität, 2001. 
Aron, R., Paix et guerre entre las nations, Paris, Calmann-Lévy, 1962.

Asbach, O., Europa - Vom Mythos zur Imagined Community? Zur historischen Semantik 'Europas'von der Antike bis ins 17. Jahrhundert, München, Wehrhahn, 2011.

Staat und Politik zwischen Absolutismus un Aufklärung. Der Abbé de Saint-Pierre und die Herausbildung der französischen Aufklärung bis zur Mitte des 18. Jahrhunderts, Hildesheim-Zürich-New York, Georg Olms, 2005.

Basso, L., Individuo e comunità nella filosofia politica di G.W. Leibniz, Sovera Mannelli, Rubbetino, 2005.

Breger, H., „Die Wissenschaften als Kennzeichen und verbindendes Band der europäischen Völker“" [in C. Roldán, ed.: Leibniz und Europa, St. Leib. SH (en prensa)].

Couturat, L., "Sur Leibniz fondateur d'Academiés" [en L. Couturat, La logique de Leibniz, Paris, Alcan, 1901].

Drouet, J., L'abbé de Saint-Pierre, l'homme et l'oeuvre, Paris, Champion, 1912.

Espinosa Antón, F.J., Inventores de la paz, soñadores de Europa, Madrid, Biblioteca Nueva, 2012.

Galtung, J., "Violence, Peace and Peace Research" [en J. Galtung, ed.: Peace: Research, Education, Action, Essays in Peace Research, vol. I, Copenhague, Christian Ejlers, 1975].

Goumy, E., Etude sur la vie et les écrits de l'Abbé de Saint-Pierre, Genève, Slatkine Reprints, 1971.

Heinekamp, A. \& Hein, I., Leibniz und Europa, Hannover, Schlütersche, 1993. Israel, J.I., Radical Enlightenment: Philosophy and the Making of Modernity 1650-1750, Nueva York, Oxford University Press, 2002.

Manuel, F. E. y Manuel, F. P., Leibniz, o el canto de cisne de la República cristiana [en Frank E. Manuel y Fritzie P. Manuel, El pensamiento utópico en el mundo occidental, Madrid, Taurus, 1984, vol. II].

Poser, H., "Die Leibnizschen Akademiepläne als Element der Einheit Europas“" [en Concha Roldán, ed.: Leibniz und Europa, St. Leib. SH (en prensa)].

Puleo, A., La ilustración olvidada, Anthropos, Barcelona, 1993.

Racionero, Q., "Politische Aufklärung und Staattheorie bei Leibniz" [en M. Buhr, ed.: Das geistige Erbe Europas, Napoles, Vivarium, 1993].

, "Racionalidad científica y racionalidad política en Leibniz" [en E. Olaso,

ed.: Leibniz: Sobre los principios, Buenos Aires, Latinoamericana de Filosofía, 1992]

Richter, L., Leibniz und sein Russlandbild, Berlin, Akad.-Vlg., 1946.

Riley, P., "Eternal Peace Through Federalism in Kant's Political Philosophy" [en P. Riley, Kant's Political Philosophy, New Yersey, Rowrnan and Littlefield, 1983]. Robinet, A., G.W.Leibniz. Le meilleur des mondes par la balance de l'Europe, Paris, PUF, 1994. 
Roldán, C., "El principio de perfección y la idea de progreso moral en Leibniz", Il cannocchiale 1 (1992).

, "Los prolegómenos del proyecto kantiano sobre la paz perpetua" [en R. R. Aramayo, J. Muguerza y C. Roldán, eds.: La paz y el ideal cosmopolita de la Ilustración (En el bicentenario de La paz perpetua de Kant), Tecnos, Madrid, 1996].

-, "Leibniz und die Europaidee" en Jahrbuch für Europäische Geschichte 2 (2001). , 'Leibniz' Concept of Europe between Nationalism and Universalism" [en A. Mogach y M. Buhr, eds.: Reason, Universality and History; Perspectives on the European intellectual Legacy, New York/Ottawa/Toronto, Legas, 2004].

—, "Transmisión y exclusión del conocimiento en la Ilustración: filosofía para damas y querelle des femmes", en Arbor 731 (2008).

- "Theoria cum Praxi: the Republic of Letters in Leibniz", en Studia Leibnitiana SH 37 (2010).

__, "La idea de tolerancia en Leibniz" [en Mª. J. Villaverde y Ch. Laursen, eds.: Forjadores de la tolerancia. Claroscuros en el pensamiento europeo de los siglos XVII y XVIII, Madrid, Tecnos, 2011].

__ "Philosophy for Ladies: diffusion or exclusion of knowledge in Enlightenment. The exclusion of women from institutionalised knowledge and the role of the salons in the dissemination of learning" [enDariuszDolański,Anna Janczys, eds.: Images offfrom Enlightenment, Zielona Góra, UZg., 2013].

Schneider, H-P., "Fürstenstaat, Reich und Europa. Leibniz zwischen dynastischen Interessen, föderativer Reichsidee und Europäischer Union", [en A. Heinekamp, ed.: Leibniz und Europa, Hannover, Schlütersche, 1994].

Seoane, J., La ilustración heterodoxa, Fundamentos, Madrid, 1998.

Totok, W., „Leibniz als Wissenschaftorganisator“ [en C. Roldán, ed.: Leibniz und Europa, St. Leib. SH (en prensa)].

Truyol y Serra, A., „Die Lehre von gerechten Krieg bei Grotius und Leibniz und ihre Bedeutung für die Gegenwart", en Studia Leibnitiana XVI/1 (1984).

Utermöhlen, G., ,Vereinigung der Konfessionen“ [en A. Heinekamp, ed.: Leibniz und Europa, Hannover, Schlüter, 1994].

York, E., Ancient, Mediaeval and Modern Leagues of Nations, London, The Swarthmore Press, 1919. 
